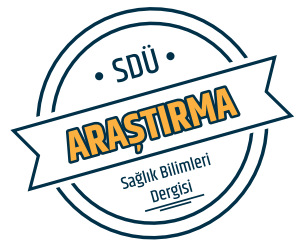

Sdü Sağlık Bilimleri Enstitüsü Dergisi / Cilt 9 Sayı 1 / 2018

\title{
Diş Çekimi Sonrası Gözlenen Alveolit Vakalarının Değerlendirilmesi
}

\author{
Evaluation of Alveolitis Cases Observed After Tooth Extraction
}

\author{
Ahmet Taylan Çebi ${ }^{1}$ \\ ${ }^{1}$ Karabük Üniversitesi, Diş Hekimliği Fakültesi, Ağız, Diş ve Çene Cerrahisi AD, Karabük, Türkiye.
}

\begin{abstract}
Özet
Amaç: Diş çekimininden hemen sonra çekim soketi kanla dolmaya başlar ve pihtı organizasyonu oluşur. Pıhtı formasyonunun oluşmadığ 1 durumlarda diş çekim yeri iltihaplanır ve ağrilı görülen bu durum alveolit olarak tanımlanır. $\mathrm{Bu}$ çalışmada alveolitin olgularının değerlendirilmesi amaçlanmıştır.
\end{abstract}

Materyal-Metot: Calıșmaya Aralık 2016- Ekim 2017 tarihleri arasında Diş Hekimliği Fakültesi, Ağız, Diş ve Çene Cerrahisi Anabilim Dalı kliniğine diş çekimi için başvurmuş ve alveolit teşhisi konmuş olan 29 hasta dahil edildi.

Bulgular: $\mathrm{Bu}$ çalışmada 2674 diş çekimi yapılan hastada 29'unda (\% 1,08) alveolit geliştiği belirlendi. Alveolit görülme sıklığı kadınlarda \% 65,5 iken, erkek hastalarda \% 34,5 olarak tespit edildi. Mandibula birinci molar bölgesinde yapılan çekimlerde daha sık alveolit geliştiği belirlendi.

Sonuç: Alveolit diş çekimi sonrasında meydana gelebilen lokal bir komplikasyondur. Sigara ve alkol kullanımı, kötü oral hijyen, travmatik diş çekimi, oral kontraseptif kullanımı alveolit oluşma riskini arttırmakta ve oluşan komplikasyon vakalarında ise şiddetli ağrıya sebep olmaktadır.

Anahtar kelimeler: Alveolit, alveoler osteit, diş çekimi.

\begin{abstract}
Objective: The extraction socket loads with blood and this blood transforms into coagulate after the dental extraction. Alveolitis is a condition with extreme pain when a coagulation disorder happens at the extraction site and this outcomes in inflammation. In this study, it was aimed to evaluation of alveolitis cases.
\end{abstract}

Material-Method: 29 patients, diagnosed with alveolitis, were included in this study patients referred to the University of Ankara, Department of Oral and Maxillofacial Surgery between December 2016-October 2017 for tooth extraction.

Results: It was determined that after 2674 teeth extraction were occured alveolitis in 29 cases (\% 1.08). The incidence of alveolitis was higher in female patiens $(\% 65.5)$ than male patients $(\% 34.5)$. It was determined that alveolitis develops more frequently in the first molar region of the mandible.

Conclusions: Alveolitis is a local complication that can often be encountered after tooth extraction. Smoking and alcohol use, poor oral hygiene, use of oral contraceptive increase the risk of alveolitis and causes severe pain inthe case of complications.

Keywords: Alveolitis, alveolar osteitis, tooth extraction.

\section{Giriş}

Diş çekimi, diş hekimlerinin ve ağız, diş ve çene cerrahlarının sıklıkla gerçekleştirdikleri dental tedavi işlemlerinin başında gelmektedir. Diş çekim işleminden sonra en çok karşılaşılan ana komplikasyonlardan biri ise alveolittir (1). Alveolit; mandibulada meydana geldiğinde kulağa ve şakak bölgesine, maksillada meydana geldiğinde ise alın ve göz çevresine kadar yayılan ağrilara, halsizlik, bitkinlik ve huzursuzluğa sebebiyet veren, cerrahi işlemden ortalama 1-3 gün sonra oluşan, pihtı formasyonunun kısmen veya tamamen bozuk olduğu ve kötü ağız kokusu ile birlikte kendini gösteren durumdur (1). Alveolit gerçekleşmesi sonucunda meydana gelen ağrı genellikle analjezik ajanlar ile hafifletilemeyen şiddette olup, ortalama 7-10 gün sürebilmektedir.

Diş çekim kavitesinin travmatize edilmesi ya da kavitenin enfekte olması sonucunda kemik iliği boşluklarında inflamasyon meydana gelmektedir. Meydana gelen bu inflamasyon hücreleri zarara uğratarak doku aktivitörlerini açığa çıkarır. Oluşan bu fibrinolitik aktivite sonucu pıhtıda var olan plazminojen plazmine dönüşür. Plazmin ise fibrin ağını bozar ve çekim kavitesinde oluşan pıhtıyı parçalanarak eritir. Ayrıca plazmin bir ağrı mediatörü olan kininin açı̆̆a çıkmasına sebep olarak ağrıya neden olur (2).

Alveolit etyolojisinde; kötü oral hijyen, oral bakteriler (özellikle trepenoma denticola), ileri derecede mevcut olan periodontal hastalık gibi lokal enfeksiyon odaklarının bulunması, travmatik diş çekimi, çekim soketinde kalan kök ve kemik parçaları, diş çekimden sonra alveolün fazla ve orantısız kürete edilmesi, oluşan pıhtı formasyonunun bozulması, oral kontraseptif ilaç kullanımı, sigara ve alkol tüketimi üzerinde durulmaktadır (1). Çekim bölgesinde 
mevcut olan lokal enfeksiyon ile alveolit oluşum riski arasında pozitif ilişki varolsa da bunlar minör etken olarak kabul edilmektedir (3-5)

Alveolitin engellenmesi için öncelikle oral hijyen optimum seviyeye getirilmelidir; iyi bir cerrahi planlama yapılmalı ve atravmatik çalışılmalıdır. Çekim sonrası sokette pıhtı varlığından emin olunmalıdır. Hastanın diş çekimini takiben sigara ve alkol kullanımını bırakması ya da çekim sonrası ilk birkaç gün ara vermesi gerekmektedir. Çekim sonrası ilk 24 saatte kuvvetli gargara yapılmaması önerilmelidir. İlaveten sistemik antibiyotikler ya da çekim kavitesine lokal antibiyotik ajan uygulanması, antiseptik ağız gargaraları veya serum fizyolojik ile gargara yapılması gibi birçok yöntem alveolit oluşumunu önlemek amacıyla kullanılabilir (4).

Alveolitin tedavisinde enfekte çekim kavitesine irrigasyon yapılarak yemek artıklarının ve enfekte dokuların soketten uzaklaştırılması sağlanır, enfekte çekim soketine pansuman yapılır ve analjezik ve antiseptik etkili lokal patlar yerleştirilir, non-steroid antiinflamatuarlar ve antiseptik ağız gargaraları reçete edilir (6).

$\mathrm{Bu}$ çalışmanın amacı, diş hekimliği cerrahisinin en çok gerçekleştirilen minör cerrahi işlemlerinden olan diş çekiminin postoperatif olarak meydana gelen komplikasyonlarından olan alveolit vakalarının olgular üzerine değerlendirilmesidir.

\section{Materyal-Method}

Bu çalışmaya Aralık 2016-Ekim 2017 tarihleri arasında Diş Hekimliği Fakültesi, Ağız, Diş, Çene Hastalıkları ve Cerrahisi Anabilim Dalı kliniğinde diş çekimi yapılan ve çekim sonrasında alveolit gelişen 29 hasta dahil edildi. Çalışma Girişimsel Olmayan Etik Kurul'unun onayı (28.12.2016 6/6) alınarak ve Helsinki İnsan Hakları Bildirisi ile ilgili kılavuz ilkelere uygun olarak yürütüldü. Çalışmaya katılan hastalara gerekli bilgilendirmeler yapıldıktan sonra 'Gönüllü Bilgilendirilmiş Onam Formu' alındı. 29 hasta anamnez sorularına göre değerlendirilip oral kontraseptif ilaç kullanımı, herhangi bir sistemik rahatsızlığg ve ilaç kullanımı olup olmadığı, sigara ve alkol kullanımı ve diş çekiminden sonra kullanmaya devam edip etmedikleri ve kullanım sıklıkları değerlendirildi. Diş çekim işlemi sırasında dişin kırılması ve flep kaldırılma ihtiyacı olduğu takdirde diş çekimi travmatik olarak sınıflandırıldı ve atravmatik çekimler değerlendirildi. Hastaların oral hijyen düzeyleri kötü: 0 , orta: 1 ve iyi: 2 olarak kaydedildi. Hastaların ağrı düzeyleri 10 cm'lik Vizüel Analog Skalası (VAS) ile değerlendirildi. Hastalardan rutinde sigara ve alkol kullandıkları, ne kadar sıklıkla alkol ve sigara kullandıkları, çekimden sonra ne kadar sigara ve alkol tükettikleri ve ne zaman sigara ve alkol tüketimi yaptıkları, yönlendirilen anket sorularıyla kayıt edildi.

\section{Bulgular}

$\mathrm{Bu}$ çalışmada; yaşları 15-81 arasında değişen 2674 diş çekim vakasının 29'unda (\% 1,08) alveolit geliştiği belirlendi. Çalışmaya 19 kadın (\% 65,5), 10 erkek (\%34,5) hasta dahil edildi (Tablo 1). Hastalardan 2 hastanın $(\% 6,9)$ oral kontraseptif kullandığı, 4 hastada $(\%$ 13,8) kardiyak problemler olduğu ve ilaç kullandığı, 3 hastada (\% 10,3) diabet rahatsızlığı olduğu ve ilaç kullandığı, 1 hastanın $(\%$ $3,4)$ prostat CA olduğu ve ilaç kullandığı, 1 hastanın ise (\% $3,4)$ hipertansiyon hastası olduğu ve ilaç kullandığı öğrenildi (Tablo 1).

Tablo 1. Hastaların demografik, sistemik bulguları ve sigara-alkol tüketimleri.

\begin{tabular}{lc}
\hline Yaş & Ortalama 37,8 \\
Cinsiyet & $19(\% 65,5)$ \\
& kadın, $10(\%$ \\
$34,5)$ erkek \\
Oral kontraseptif kullanımı & $\% 6,9$ \\
Kardiyak problemler ve ilaç kullanımı & $\% 13,8$ \\
Diabet ve ilaç kullanımı & $\% 10,3$ \\
Prostat CA ve ilaç kullanımı & $\% 3,4$ \\
Hipertansiyon ve ilaç kullanımı & $\% 3,4$ \\
Sigara kullanımı & $\% 75,9$ \\
Diş çekiminden sonra sigara kullanımı & $\% 81,9$ \\
Alkol kullanımı & $\% 48,3$ \\
Diş çekiminden sonra alkol kullanım & $\% 100$ \\
\hline
\end{tabular}

29 hastanın 22'sinin (\% 75,9) sigara kullandığı ve bunların 18 'inin $(\%$ 81,9) diş çekim yapıldı ğı günde dahil olmak üzere çekimden sonra sigara kullanımına devam ettikleri öğrenildi. Sigara kullanan hastaların 11 'inin (\% 50) günde 1 paketten fazla sigara içtikleri ve tamamının ise ortalama günde 10'dan fazla sigara tükettikleri öğrenildi. 29 hastanın 14'ünün (\% 48,3) alkol kullandığı ve bunların tamamının da çekimden sonra alkol kullanmaya devam ettikleri tespit edildi. Alkol kullanan hastalar içinden sadece 1'inin $(\% 7,1)$ hemen hemen her gün alkol tüketimi yaptığı öğrenildi (Tablo 1).

Oral hijyen değerlendirilmesi yapıldığında 18 hastanın (\% $62,1)$ oral hijyen bakımından zayif, 9 hastanın (\% 31) orta seviyede ve 2 hastanın $(\% 6,9)$ oral hijyeninin iyi olduğu belirlendi (Şekil 1).

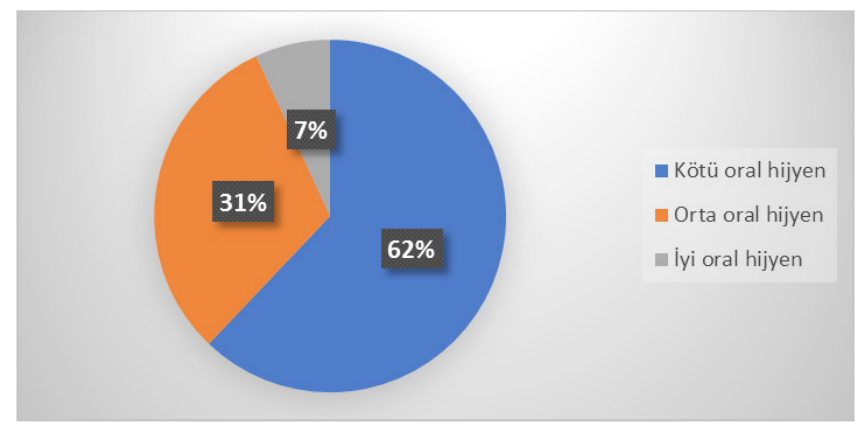

Şekil 1. Alveolit olgularındaki oral hijyen düzeyleri. 
Alveolit görülen dişlerden 16 diş ( $\% 55,2)$ alt molar bölgeden, 8 diş (\% 27,6) alt premolar bölgeden, 5 diş (\% 17,2) ise üst molar bölgeden çekildi. Diş çekimleri atravmatik olarak gerçekleştirildi (Şekil 2).

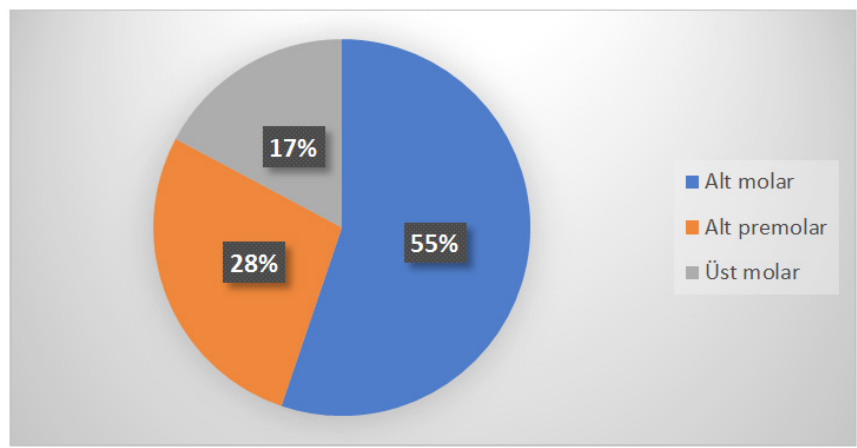

Şekil 2. Alveolit olguların diş gruplarına göre dağılımı.

Hastalardan 20'sinin (\% 68,9) ağrı seviyesinin çok şiddetli ve dayanılmaz, 9'unun ise (\% 31,1) hafif ve orta seviyeli şiddetli olduğu tespit edildi (Tablo 2).

Tablo 1. Hastaların demografik, sistemik bulguları ve sigara-alkol tüketimleri.

\begin{tabular}{lll}
\hline & $\begin{array}{l}\text { Çok şiddetli ağrı } \\
\text { düzeyi }\end{array}$ & $\begin{array}{l}\text { Hafif ve orta } \\
\text { Seviyeli ağrı } \\
\text { düzeyi }\end{array}$ \\
Hasta sayısı & 20 & 9 \\
Hasta yüzdesi & $\% 68,9$ & $\% 31,1$ \\
\hline
\end{tabular}

\section{Tartışma}

Diş çekim sonrası meydana gelen komplikasyonlardan olan alveolitin oluşma sıklığı üzerine yapılan araştırmalarda, bu komplikasyonun değişik oranlarda meydana geldiği belirtilmektedir. Alexander (3) yaptığı çalışmada 2720 adet 3. molar diş çekiminden sonra herhangi bir intraalveoler medikasyon kullanmaksızın \% 3,12 alveolit oranı bulmuştur. Güngörmüş ve ark. (7) 4104 atravmatik diş çekiminden sonra \% 1,3 sıklıkla alveolit oluştuğunu belirtmişlerdir. Öğütcen ve ark. (8) gömük alt yirmi yaş dişlerinin cerrahisi sonrasında toplam alveolit oranını \% 29 olarak tespit etmişlerdir. Bu çalışmada 2674 atravmatik diş çekimi olgusundan \% 1,08 oranında alveolit geliştiği belirlenmiştir.

Monaco ve ark. (9), yaptıkları çalışmalarında kadın hastaların alveolit komplikasyonuna daha yatkın olduklarını belirtmişlerdir. Sweet ve ark. (10), çalışmalarında çekim sonrası alveolit görülme sıklığında cinsiyetin etkisine bakmışlar ve kadın hastalarda alveolit görülme sıklığını \% 4,1 bulurlarken erkek hastalarda ise \% 0,5 olarak bulmuşlardır. Bu çalışmada 29 hastanın \% 65,5'i kadın olup bu veriyi desteklemiştir.

Alveolit en fazla alt molar, alt premolar, üst premolar ve üst molar dişlerin çekiminden sonra meydana gelmektedir (7). Alveolit, mandibular molar dişlerde maksiller molar dişlere göre on kat daha fazla görülmektedir (11). Güngörmüş ve ark. (7), yaptıkları araştırmalar sonucunda alveolitin en fazla alt 1. Molar diş çekiminden sonra ve \% 65 'inin alt çenede olduğunu belirtmişlerdir. $\mathrm{Bu}$ çalışmada alveolit görülen 29 çekim soketinin \% 55,2' si alt molar dişler, \% 27,6's1 alt premolar dişler ve \% 17,2'si ise üst molar dişlerdir.

Travmatik diş çekimi ve dişteki lokal enfeksiyon varlığı ile alveolit gelişmesi arasında ilişki olduğu, travmatik çekimin ve dişteki mecvut lokal enfeksiyonun alveolit gelişimini arttırdığ1 bilinmektedir (6). Çalışmamızda, diş çekim sırasında dişin kırılması ve flep kaldırılarak çıkarılması travmatik çekim olarak değerlendirilmiştir ve alveolit olgularının tamamında da atravmatik çekim uygulanmıştır.

Penarrocha ve ark. (12), yaptıkları çalışmada, gömülü 3.molar diş cerrahisi öncesi oral hijyen ile postoperatif ağrı, inflamasyon, trismus ve alveolit oluşumu arasındaki ilişkiyi araştırmışlar ve sonuç olarak kötü oral hijyenin daha fazla ağrı ile ilişkili olduğunu bulmuşlardır. Çalışmamızda, alveolit oluşan hastaların \% 62,1'i oral hijyen bakımından zayıf, \% 31 'i orta seviyede ve $\% 6,92$ 'unun ise oral hijyeninin iyi olduğu belirlendi.

Sigara tüketimi, nötrofillerde kemotaksis ve fagositoz yapmakta ve ayrıca immunoglobilin yapımını engellemektedir (13). Meechan ve ark. (14), yaptıkları çalışmada alveolit oluşumunda sigaranın etkilerini incelemişler ve sigara kullanımının diş çekim soketine kan dolmasını engellediğini ve sigara kullanan bireylerde sigara kullanmayan bireylere oranla alveolit görülme sıklığının daha fazla olduğunu bildirmişlerdir. Sweet ve ark. (10), araştırmalarında diş çekimin yapıldığı gün sigara tüketimi yapıldığında alveolit görülme olasılığının daha yüksek olduğunu bildirmişlerdir. Bu çalışmada alveolit gelişen 29 hastanın \% 75,9'unun sigara kullandıkları, sigara kullananların ise \% 81,9'unun diş çekim işlemi yapıldığı gün ve sonrasında da sigara tüketmeye devam ettikleri bildirilmiştir. Sigara kullanan hastaların \% 50'sinin günlük 1 paketten fazla sigara tükettiği, tamamının ise ortalama olarak günlük 10 adetten fazla sigara içtiği tespit edilmiştir.

Alkol kullanımı, kardiomiyopati, anemi, kardiyak ve nörolojik sorunlar yaratmaktadır (15). Aşırı alkol tüketimine bağlı olarak meydana gelen karaciğer fonksiyon bozuklukları pıhtılaşma problemlerine yol açabilmektedir. Pıhtılaşma problemi ise yara iyileşmesini olumsuz yönde etkilemekte ve çekim soketlerinde lokal enfeksiyonlara neden olabilmektedir. Ayrıca alkol tüketimi immün sistemi baskılayıcı etkide bulunmaktadır (16). Çalışmamızda da diş çekimi sonrası lokal enfeksiyon olarak alveolit görünen vakaların \% 48,3'ünün alkol kullandığ 1 ve alkol kullanan hastalarda ağnı seviyelerinin yüksek olduğu tespit edilmiştir. 


\section{Sonuç}

Sonuç olarak, alveolit diş çekim işlemi sonrasında karşılaşılan lokal komplikasyonların başında gelmektedir. Alt çenede ve özellikle büyük azılar bölgesindeki çekimlerde daha fazla alveolit oluşmaktır. Alveolit oluşmasını engellemek ya da en aza indirmek için hastalarda çekim öncesi ve sonrası oral hijyenin en iyi seviyede tutulmasını sağlamanın, atravmatik çalışmaya özen göstermenin, sigara ve alkol tüketiminin alveolite zemin hazırladığını ve postoperatif olarak ağrı seviyesini yükselttiğini bilmenin ve hastalara belirtmenin

etkili olduğu kanaatindeyiz.

\section{Kaynakça}

1. Blum İR: Contemporary views on dry socket (alveolar osteitis): a clinical appraisal of standardization, aetiopathogene- sis and management: a critical revievv. Int J Oral Maxillofac Surg 2002; 31: 309-317.

2. Neville BW, Damm DD, Ailen CM, Bouquot JE. Oral and Maxillofacial Pathology. W.B. Saunders Company, Philadelphia 1995; p.119.

3. Alexander RE. Dental extraction wound management. A case against medicating postextraction sockets. J Oral Maxillofac Surg 2000; 58: 53851.

4. Bloomer CR: Alveolar osteitis prevention by immediate placement of medicated packing. Oral Surg Oral Med Oral Pathol Oral Radiol Endod 2000; 90(3): 282-284.

5. Cheung LK, Chow LK, Tsang MH, Tung LK. An evaluation of complications following dental extractions using either sterile or clean gloves. Int J Oral Maxillofac Surg 2001; 30: 550-4.

6. Yoshii T, Hamamoto Y, Muraoka S, Furudoi S, Komori T. Differences in postoperative morbidity rates, including infection and dry socket, and differences in the healing process after mandibular third molar surgery in patients receiving 1-day or 3-day prophylaxis with lenampicillin. J Infect Chemother 2002; 8: 87-93.
7. Güngörmüş M, Yıldırım G, Gürbüz G: Alveoler osteiti- sin etyolojisi ile ilişkili klinik parametrelerin risk oranlarının de ğerlendirilmesi. OMÜ Dişhekimliği Fakültesi Dergisi 2001; 2(5): 44-47.

8. Öğütcen M, Yılmaz D: Gömülü alt yirmi yaş dişleri nin çıkarılmasında kanama ve lokalize alveolitis oluşumunun değerlendirilmesi. G.Ü. Dişhek Fak Der 1989; 6(1): 147-157.

9. Monaco G, Staffolani C, Gatto MR, Checchi L. Antibiotic therapy in impacted third molar surgery. Eur J Oral Sci 1999; 107: 437-41.

10. Sweet JB, Butler DP. Predisposing and operative factors: effect on the incidence of localized osteitis in mandibular third molar surgery. Oral Surg Oral Med Oral Pathol Oral Radiol Endod 1978; 46: 206-15.

11. Alling III CC, Helfrick JF, Alling RD. Impacted teeth, Saunders, Philadelphia 1993; p.371.

12. Penarrocha M, Sanchis JM, Saez U, Gay C, Bağan JV. Oral hygiene and postoperative pain after mandibular third molar surgery. Oral Surg Oral Med Oral Pathol Oral Radiol Oral Endol 2001; 92: 260-4.

13. Larsen PE. Alveolar osteitis after surgical removal of impacted mandibular third molars: Identification of the patient at risk. Oral Surg Oral Med Oral Pathol 1992; 73: 393-7

14. Meechan JG, Macgregor DM, Rogers SN, Hobson RS, Bate JPC, Dennison M. The effect of smoking on immediate post-extraction socket filling with blood and on the incidence of painful socket. Br J Oral Maxillofac Surg 1988; 26: 402-9.

15. İlhan İÖ, Demirbaş H, Yarpuz AY, Doğan YB. Alkol bağımlılığında remisyon süresi üzerinde etkili olan değişkenler. Bağımlılık Dergisi 2003; 4(2): 57-61. 39.

16. Akvardar Y, Turkcan A, Yazman U, Aytaçlar S, Ergor G, Cakmak D. Prevalance of alcohol use in İstanbul. Psychol Rep 2003; 92: 1081-8. 